Purpose To evaluate the diagnostic performance and safety of intravesical administration of a-second-generation ultrasound contrast-agent (UCA) for the diagnosis of vesicoureteric reflux (VUR) in children.

Methods and materials 1350 children (587 boys/763 girls, mean-age $2.6 \mathrm{y}$, range $15 \mathrm{~d}-17 \mathrm{y}$ ) with 2720 pelvi-ureter-units, underwent contrast-enhanced voiding urosonography (ceVUS) to rule out VUR and urethral pathology. A second-generation UCA (SonoVue ${ }^{\circledR}$, Bracco, Milan) was administered intravesically through $5-8 \mathrm{~F}$ feeding-tube at a dose of $0.5 \mathrm{ml} / \mathrm{bladder}$ filling. Possible adverse-events were monitored during the examination and followed-up for 7 days after the ceVUS by phone-calls. Urine analysis and culture were performed 3-5 d before ceVUS in all children and $24-48 \mathrm{~h}$ in any patient reported with adverse-events.

Results VUR was detected in 450/1350(33\%) patients (162 boys/288 girls). This was in 653 pelvi-ureter-units (reflux-grade distribution: grade $\mathrm{I}=1$, grade $\mathrm{II}=276$, grade $\mathrm{III}=266$, grade IV $=100$, grade $\mathrm{V}=10$ ). The urethra was normal in all children. Mean duration of examination was $14 \pm 7 \mathrm{~min}$, including urethral imaging. Minor adverse-events were reported in 45 (3.3\%) children. These included dysuria $(\mathrm{n}=39)$, abdominal pain $(n=2)$, increased frequency of micturition $(n=1)$, vomiting $(\mathrm{n}=1)$, perineal irritation $(\mathrm{n}=1)$, and urinary-tract-infection after ceVUS $(n=1)$. The onset of adverse-events were subacute in $92 \%$ and delayed in $8 \%$ and were self-limited nonrequiring hospitalisation.

Conclusions There were no serious adverse-events with intravesical use of SonoVue ${ }^{\circledR}$. Only a few minor adverse-events were reported during ceVUS most likely due to catheterization process. Thus ceVUS with intravesical administration of a second generation UCA (SonoVue ${ }^{\circledR}$ ) for VUR and urethral pathology detection is a safe and reliable diagnostic procedure in children.

\section{PS-238 STUDY OF BONE BIOCHEMICAL MARKERS AND THE CYTOKINE SRANKL/OPG SYSTEM IN CHILDREN WITH IDIOPATHIC HYPERCALCIURIA}

${ }^{1}$ M Pavlou, ${ }^{1} \mathrm{E}$ Siomou, ${ }^{2} \mathrm{~A}$ Challa, ${ }^{1} \mathrm{D}$ Kourou, ${ }^{1} \mathrm{~A}$ Siamopoulou. ${ }^{1}$ Paediatrics, University Hospital of Ioannina, Ioannina, Greece; ${ }^{2}$ Paediatrics Research Laboratory, University Hospital of loannina, Ioannina, Greece

\subsection{6/archdischild-2014-307384.537}

Background Idiopathic Hypercalciuria (IH) has been associated with decreased bone density up to $30 \%$ of the children.

Aims To determine the concentrations of cytokines osteoprotegerin (OPG) and sRANKL and other biochemical indices of bone metabolism in children with $\mathrm{IH}$.

Methods In 31 children of median age 6.3 years (range 2.216.4) with IH OPG, sRANKL, 25(OH)D, 1,25(OH $)_{2} \mathrm{D}, \mathrm{PTH}$, $\mathrm{Ca}, \mathrm{Pi}$, osteocalcin, ALP and CTx-Crosslaps were determined in serum and $\mathrm{Ca} / \mathrm{Cr}$, oxalate $/ \mathrm{Cr}$ and citrate/Cr in urine. Times of study were at diagnosis and after 3 months of salt free and adequate $\mathrm{Ca}$ diet. Height and BMI z-score were assessed. Clinically healthy children $(\mathrm{n}=35)$ matched for age/sex and season were used as controls (median 7.8 years, range 1.8-16.3).

Results Although urinary Ca excretion $(24 \mathrm{hCa}$ and $\mathrm{UCa} / \mathrm{UCr}$ ) decreased at 3 mo $(p<0.05$ and $p<0.01)$ on average it had not reached control values $(\mathrm{p}<0.0001, \mathrm{p}=0.0004)$. No significant differences were found for urine excretion of citrate and oxalate or for serum $\mathrm{Ca}, \mathrm{Pi}, 25 \mathrm{OHD}, 1,25(\mathrm{OH})_{2} \mathrm{D}, \mathrm{PTH}$, osteocalcin, ALP, OPG, sRANKL and sRANKL/OPG ratio in patients before and after diet or compared to controls. Only serum concentrations of CTx-Crosslaps were significantly higher in both patient samples $(p<0.02, p<0.05)$ than controls. The BMI $z$-score was lower in patients than controls $(\mathrm{p}=0.016)$, but height did not differ.

Conclusion Although serum OPG/sRANKL and osteocalcin were not different in children with $\mathrm{IH}$, the higher serum CTx-Crosslaps levels (bone resorption index) may suggest bone turnover uncoupling with an autocrine role of the above cytokines.

\section{PS-239 EARLY ACUTE RENAL INJURY VERSUS LATE ACUTE RENAL INJURY. ARE THERE ANY PROGNOSTIC DIFFERENCES BETWEEN THEM?}

A Jiménez, A Haro, C Torres, P Salgado, MJ Santiago, AJ Alcaraz, SN Fernandez. PICU, Hospital General Universitario Gregorio Marañón, Madrid, Spain

\subsection{6/archdischild-2014-307384.538}

Objectives To evaluate the clinical differences betweenpatients developing early acute kidney injury (EAKI) and late acute kidneyinjury (LAKI) during their stay in a PICU.

Methods Retrospective study including patients admitted to the PICU over the last 4 years. Children were excluded if they had a length of stay of less than 2 days or if they had end stage renal disease. AKI was defined according to the KDIGO criteria. The episodes of AKI that began within the first $72 \mathrm{~h}$ of admission were considered early AKI (EAKI), and those that appeared later were considered LAKI.

Results 1082 patients fulfilled the inclusion criteria. 415 patients (38.3\%) developed AKI: EAKI 354 patients (173 had stage I AKI, 77 stage II and 104 stage III); 61 patients LAKI (33 stage I, 15 stage II and13 stage III). The severity and duration of the $\mathrm{AKI}$, the need for dialysis and the incidence of pre renal AKI were not different between EAKI and LAKI groups. Patients with LAKI had more time of mechanical ventilation $(156 \mathrm{~h}$ vs $72 \mathrm{~h}, \mathrm{p} 0.006)$ and a longer PICU stay (13 vs 7 days, $\mathrm{p}<0.001$ ). There were no differences in age or mortality between groups. LAKI was found to be more frequent in post-operative cardiac patients $(41 \%)(\mathrm{p}<0.001)$.

Conclusions LAKI is associated with more time of MV, longer PICU stay and with the cause of admission to the PICU. However LAKI is not associated with greater severity or mortality than EAKI.

\section{PS-240 DEVELOPING A TOXIC PAEDIATRIC ANIMAL MODEL OF NON-OLIGURIC ACUTE RENAL INJURY WITH CISPLATIN}

MJ Santiago, J López-Herce, J López, J Urbano, R González, MJ Solana, SN Fernandez, B Toledo. PICU, Hospital General Universitario Gregorio Marañón, Madrid, Spain

\subsection{6/archdischild-2014-307384.539}

Introduction Developing a non-oliguric paediatric animal model of acuterenal injury (AKI) could be useful to study the evolution of diuresis after treatments. Cisplatin causes a dose-dependant poliuric renal failure in humans. A dose of $5 \mathrm{mg} / \mathrm{kg}$ has been used in rats to produced AKI but there are no studies in pigs. 


\begin{tabular}{|c|c|c|c|c|c|c|c|}
\hline Cisplatin & Days & Initial & & Urea & & & \\
\hline $\begin{array}{l}\text { dose } \\
\mathrm{mg} / \mathrm{kg}\end{array}$ & $\begin{array}{l}\text { after } \\
\text { inyection }\end{array}$ & $\begin{array}{l}\text { diuresis } \\
(\mathrm{m} / \mathrm{h})\end{array}$ & $\begin{array}{l}\text { Creatinine } \\
(\mathrm{mg} / \mathrm{dL})\end{array}$ & $\begin{array}{l}\text { (mg/ } \\
\mathrm{dL})\end{array}$ & $\begin{array}{l}\text { Sodium } \\
\text { (mmol/L) }\end{array}$ & $\begin{array}{l}\text { Potasium } \\
(\mathrm{mmol} / \mathrm{L})\end{array}$ & $\begin{array}{l}\text { Phosphate } \\
\text { (mg/dL) }\end{array}$ \\
\hline 2 & 4 & - & 1.0 & 46 & 140 & 4.3 & - \\
\hline 2 & 4 & 31 & 0.9 & 45 & 138 & 4.5 & 6.8 \\
\hline 3 & 2 & 20 & 3.6 & 174 & 138 & 4.6 & 13.5 \\
\hline 3 & 2 & 22 & 1.5 & 142 & 135 & 3.4 & 15 \\
\hline 3 & 2 & 38 & 4.2 & 209 & 132 & 5.9 & 16 \\
\hline 3 & 2 & 30 & 3.8 & 189 & 137 & 4.2 & 15.8 \\
\hline 3 & 4 & 7 & 9.5 & 518 & 137 & 8.7 & 20.3 \\
\hline 5 & 3 & 1 & 5.5 & 409 & 120 & 10.4 & 14.8 \\
\hline
\end{tabular}

Objectives To define the target dose of Cisplatin that develops anon-oliguric toxic acute kidney injury in piglets.

Methods A prospective experimental study was performed in 8 piglets (mean $10 \mathrm{~kg}$ ). Three different intravenous doses of Cisplatin $(2,3$ and $5 \mathrm{mg} / \mathrm{kg}$ ) and two different periods of time between administration and evaluation ( 2 and 4 days) were studied. Urine and blood samples were collected.

Results Results are presented in Table 1. A dose of $2 \mathrm{mg} / \mathrm{kg}$ did not produce important alteration of renal function at any given time. A very severe oliguric AKI with extremely high hyperkalemia was observed four days after a $3 \mathrm{mg} / \mathrm{kg}$ dose and 3 days after a $5 \mathrm{mg} / \mathrm{kd}$ dose. A dose of $3 \mathrm{mg} / \mathrm{kg}$ administrated $48 \mathrm{~h}$ before produced an important AKI without severe hyperkalemia. Conclusions A dose of $3 \mathrm{mg} / \mathrm{kgof}$ intravenous cisplatin producednon-oliguric AKI after $48 \mathrm{~h}$ in piglets. This dose and interval can be used for toxic paediatric animal models of AKI.

\section{PS-241 WITHDRAWN}

\section{PS-242 RITUXIMAB IN THE TREATMENT OF MINIMAL CHANGE DISEASE IN CHILDREN WITH NEPHROTIC SYNDROME}

XL Niu, S Hao, P Wang, GH Zhu, Y Wu, W Zhang, GM Guo, WY Huang. Nephrology and Rheumatology, Shanghai Children's Hospital Shanghai Jiaotong University, Shanghai, China

\subsection{6/archdischild-2014-307384.540}

Background and aims To explore the efficiency and side effects of rituximab in the treatment of minimal change disease (MCD) in children with steriod-dependent nephrotic syndrome (SDNS). Methods From 2011.10 to 2014.4, children with MCD who hospitalised alwaysrelapsed although treated with steroid and one or more immunosuppressants. Thenthey were given rituximab 1 or 2 times $\left(375 \mathrm{mg} / \mathrm{m}^{2}\right)$.

Results Fifteen patients (male: female 7:8)with MCD, ageing from 4-17 years old $(7.93 \pm 3.26$ years old $)$ were followed up for 2-30 months (15.4 \pm 9.86 months). After infusion of rituximab, the B cell was obviously decreased $(\mathrm{CD} 20<1 \%, \mathrm{~T}=110$, $\mathrm{PT}=4, \mathrm{PT}=91, \mathrm{PT}=1, \mathrm{P}$ Side effect: Only two patients got mildly uncomfortable in the infusion of rituximab but relieved with decreasing the rate of infusion.

Conclusion Rituximab has efficiency in treating children with MCD. It can help to reduce the dosage of steroids. And maybe one time of rituximab is enough for children with MCD. And there are no seriously side effects of rituximab.

\section{PS-243 \\ THE CLINICAL SIGNIFICANCE OF URINARY NEUTROPHIL GELATINASE ASSOCIATED LIPOCALIN, KIDNEY INJURY MOLECULAR-1 AND INTERLEUKIN-18 IN ACUTE KIDNEY INJURY AFTER CHILDHOOD RDIOPULMONARY BYPASS}

${ }^{1} \mathrm{HJ}$ Liu, ${ }^{1} Y L$ Shen, ${ }^{1} \mathrm{~L}$ Sun, ${ }^{1} \mathrm{XY}$ Kuang, ${ }^{2} \mathrm{RF}$ Zhang, ${ }^{3} \mathrm{H}$ Zhang, ${ }^{2} \mathrm{XB} \mathrm{Li},{ }^{1} W Y$ Huang. ${ }^{1}$ Nephrology and Rheumatology, Shanghai Children's Hospital Shanghai Jiaotong University, Shanghai, China; ${ }^{2}$ Cardiothoracic Surgery, Shanghai Children's Hospital Shanghai Jiaotong University, Shanghai, China; ${ }^{3}$ Clinical Laboratories, Shanghai Children's Hospital Shanghai Jiaotong University, Shanghai, China

\subsection{6/archdischild-2014-307384.541}

Background and aims To investigate the value of urinary neutrophil gelatinase associated lipocalin (NGAL) kidney injury molecular1 (KIM-1) and interleukin-18 (IL-18) in the diagnosis of acute kidney injury (AKI) following childhood cardiopulmonary bypass (CPB).

Methods 67 patients accepted CPB assigned to acute kidney injury group (group AKI) ornon-acute kidney injury group (group non-AKI). Samples were taken regularly after CPB 30 min, $2 \mathrm{~h}, 4 \mathrm{~h}, 24 \mathrm{~h}, 48 \mathrm{~h}$ and $72 \mathrm{~h}$.

Results The incidence of AKI was 34\%, including 15 cases with Risk stage AKI, 4 cases with Injury stage AKI, 3 cases with Failure stage AKI, 1 cases with Loss stage AKI. Comparing with the non-AKI group, the levels of urinary NGAL/Cr was much higher than that of controls after CPB $24 \mathrm{~h}$. The levels of urinary NGAL/Cr were higher than that of controls after CPB $48 \mathrm{~h}$. The values for the AUC were determined for urine KIM-1 as 0.698 and 0.662 after CPB $24 \mathrm{~h}$ and $48 \mathrm{~h}$. Comparing with the preoperation, the levels of urinary IL-18/Cr were higher than that of controls after CPB $30 \mathrm{~min}$. AKI group has a higher level than that of non-AKI group after CPB $4 \mathrm{~h}$.

Conclusion In this study, our results identify that possibly urine NGAL, KIM-1 and IL-18 are more significative than Scr for early detection. However, the exact clinical value needs to be further elucidated.

\section{PS-244 ACETAZOLAMIDE TREATMENT FOR METABOLIC ALKALOSIS IN A PAEDIATRIC INTENSIVE CARE UNIT}

B Toledo, A Alcaraz, C Arribas, M García, E Fernández, P Paredes, MJ Santiago. Pediatric Intensive Care Unit, Hospital General Universitario Gregorio Marañón, Madrid, Spain

10.1136/archdischild-2014-307384.542

Study

Objective To evaluate the efficacy of enteral acetazolamide treatment for hypochloraemic metabolic alkalosis in critically ill children.

Methods We designed an observational retrospective study that included critically ill children admitted to the PICU from January 2010 to December 2013 and treated with acetazolamide for at least $48 \mathrm{~h}$ for metabolic alkalosis. We recorded demographic data, dose and type of diuretic treatment, use of mechanical ventilation and acid-base and biochemical data. Acetazolamide was administered enterally and both dose and adverse effects were collected.

Results A total of 120 episodes of treatment (86 post-cardiac surgery, 17 cardiac decompensations and 17 patients with respiratory disease) in 93 patients (median age 6 months) were analysed.

$85 \%$ received a continuous IV furosemide infusion and 14.2\% intermittent bolus administration of furosemide. Furosemide doses of patients with respiratory disease were lower $(\mathrm{p}<$ $0,001)$ than in patients with other pathologies. 